\title{
Social Learning, Critical Reflection and the Perception of Facticity in Deliberation on Water Reuse
}

\author{
Greg Hampton ${ }^{1}$ \\ ${ }^{1}$ Academic Services Division, University of Wollongong, New South Wales, Australia \\ Correspondence: Greg Hampton, Academic Services Division, University of Wollongong, Northfields Ave, \\ Gwyneville, 2522, New South Wales, Australia. Tel: 61-2-4221-446. E-mail: greg_hampton@uow.edu.au
}

Received: September 17, $2012 \quad$ Accepted: November 5, 2012 Online Published: November 26, 2012
$\begin{aligned} & \text { doi:10.5539/res.v4n5p181 } \\ & \text { URL: http://dx.doi.org/10.5539/res.v4n5p181 }\end{aligned}$

\begin{abstract}
Critical reflection involves the uncovering and understanding of the assumptions, which are made in the development of knowledge and the establishment and perception of facts. A capacity to understand the development of facts is proposed as an important outcome of social learning. The public perception of the facticity of expert scientific and technological knowledge is analysed in four sets of workshops conducted with publics who utilised recycled water, were within close proximity to water recycling schemes or lived in an area where planned water recycling schemes were to be implemented. The purpose of these workshops was to develop a social learning method, which could be utilised within public engagement about water reuse management. Jonathan Potter's concepts of offensive and defensive rhetoric and reifying and ironising discourse were used to describe how a public perceived expert knowledge as factual or resisted the facticity of expert pronouncements about water reuse, which were utilised in the workshops. Examples of this type of rhetoric and discourse were identified in the deliberative workshops developed in this study of social learning about water reuse and its implementation in public engagement.
\end{abstract}

Keywords: social learning, facticity, expert knowledge, public engagement

\section{Social Learning, Critical Reflection and the Perception of Facticity in Deliberation on Water Reuse}

In Australia, in the last decade, the consideration by governments and publics of water reuse in the provision of rural and urban water supplies has become critical. A process of social learning, that we developed in a series of workshops designed for use in an engagement process for public consideration of water reuse, focused on public understanding of expert knowledge about water reuse and public capacity to reflect on the expertise presented to them. We wanted to instil in the public the capacity to question expertise and to consider whether the information presented by experts was an opinion and not necessarily an established fact. We assessed whether the publics in our workshops could readily question the expert information provided to them rather than readily accept such expertise. Our interest in this approach was in part instigated by the readiness of the expertise engaged by the water reuse industry to proclaim how scientific and technological understanding of the safety of water reuse was factual.

Readiness to claim the safety of water reuse as factual was evident in a controversy concerning recycled water in Toowoomba, Queensland, Australia. In this situation the local government did not engage the public in a robust process of social learning. The funding provisions of the federal government required the public to give their opinion on water recycling within a short timeframe, which precluded the local government from engaging the public in a social learning process on recycled water. Rather than providing the public with the opportunity for critical reflection on the scientific and technological aspects of water recycling the local government engaged the public in a marketing program designed to convince them of the worth of water recycling. This was typified by the statements of a water scientist, who was employed by the Toowoomba Council and portrayed as an expert providing the facts about recycled water, who concurred after conducting a review of the scientific literature that it was safe to reuse highly treated effluent in the water supply. There was considerable opposition in the local community towards recycled water being added to the local water supply. A local businessman joined forces with a community action group and funded this group so that it became very vocal in the local media. This group was vociferous in its rejection of the commonly accepted scientific facts (Waste Management Environment, 2012). The local community eventually voted in a referendum, to not proceed with a water recycling project employing 
advanced water treatment. The stance of presenting the facts rather than promoting critical reflection on the scientific and technological knowledge presented to citizens, is the focus of this article. What I am proposing is that a social learning process, whereby people meet together to learn about technology and engage in critical reflection on the information presented, will enable citizens to more readily engage with the information provided on the science and technology involved and accept or question the facticity of such information.

The construction and perception of scientific facts has undergone considerable study in the area of science and technology studies and the philosophy of science. A large body of work has developed, which describes how scientific facts have been constructed by particular individuals with particular theoretical perspectives, and sometimes ideological biases and political positions, which have influenced their particular views and conclusions on the construction of these facts (Burchell, 2007; Chalmers, 1982; Petts, 1997). A particular observation might be considered a fact, which bolsters a particular theory, but might not be considered factual by another scientist who has a differing theory explaining the occurrence of the phenomenon. The expertise presented in the deliberative workshops conducted in this study was primarily provided by a science and technology academic, who had expertise in the interpretation of scientific knowledge and also had degrees in the physical sciences. He was able to discuss with participants where there was a particular controversy concerning water treatment and the science involved.

Social learning is critical to the process of developing citizen proficiency in understanding science and technology. It is designed "to enlarge the citizen client's abilities to pose the problems and questions that interest and concern them and to help connect them to the kinds of information and resources needed to help them find answers" (Fischer, 2000). In social learning, how people perceive their personal interests are compared to and connected with the shared interests of their community (Webler, Kastenholz, \& Renn, 1995). Conditions must be right for meaningful dialogue and interaction to occur between experts and non-experts that results in an environment for thinking and learning together. Some aspects of a program that can promote social learning include providing an atmosphere of open dialogue and transparency of information, opportunities for repeated meetings and gatherings, access to expert support, face to face small group work, site visits and tours, unrestricted opportunities to influence the program process, and political support for the process (Webler, et al., 1995). These aspects of social learning can be used to develop a public's capacity to reflect on and question scientific knowledge presented to them. Social learning is particularly appropriate to deliberation about water reuse where communities are often divided on the reuse of water and need to carefully and collectively review the efficacy of water treatment technology.

Social learning is different from individual learning. "Public participation can initiate social learning processes which translate uncoordinated individual actions into collective actions that support and reflect collective needs and understandings" (Webler, et al., 1995). Social learning "as learning occurs when people engage one another, sharing diverse perspectives and experiences to develop a common framework of understanding and basis for joint action" (Schusler, Decker, \& Pfeffer, 2003). Public adoption of new technology is dependent upon the use of sound methods of social learning within communities, which generate a collective interest in understanding and using such technology.

Implementation of methodologies such as participatory inquiry, as proposed by Fischer (2000, 2003), indicate that communities are more capable of interpreting technical information than is commonly accepted. Participatory inquiry is a process whereby a community is assisted to set and answer its own questions and examine technical issues in its own languages (Fischer, 1993) and facilitates collaboration and exchanges between citizens and experts and the process whereby a public become aware of the way in which scientific and technological facts are produced (Fischer, 2000). The general approach of participatory inquiry was similar to the method adopted in the deliberative workshops developed for this study.

The development of a social learning strategy in which citizens grapple with scientific and technological knowledge in public engagement programs is reinforced in public policy literature. Reich (1990) suggests that public managers should engage with the public through deliberation and education in a process of civic discovery. The goal of deliberation is that people learn from each other rather than pursuing a set of pre-existing facts and develop the capacity to question the technical information provided to them in an engagement program. Eden (1996) suggests that public participation in policy development can be promoted through public exposure to and demystification of science. This might be achieved through the development of counter expertise derived from other scientists or publics who develop technical competence through self-education. This can be achieved by training publics to question the information provided to them in an engagement program and how this can be achieved will be described in a later section describing the workshop process used in this study. The development of citizen competence to make judgments about scientific expertise through social learning is 
important in an era of new public management where emphasis is placed on public choice, rational self-interest, contractual obligations (den Heyer, 2011) and network governance (Radcliffe \& Dent, 2005) where citizen competence to make informed judgments in collaboration with business and government is critical (Agranoff \& McGuire, 2004). In the following sections I review the role of critical reflection in social learning and use Jonathan Potter's (1996) concepts of reificatory and ironizing discourse and offensive and defensive rhetoric to delineate processes of critical reflection, or alternatively, uncritical acceptance of expertise in processes of social learning.

\subsection{Social Learning and Critical Reflection}

Keen, Brown and Dyball (2005), in reviewing social learning in environmental management, ask how social learning relates to different ways of knowing and engaging. They propose a model of social learning comprised of reflection, systems orientation, integration, negotiation and participation. They suggest that different forms of participation with different forms of social learning might be appropriate at different stages of a participatory process depending on learning and management objectives. Reflecting on learning leads to new learning and an awareness of how cultural and political contexts affect actions and values (Keen, et al., 2005). The following social learning literature has dealt with the issue of critical reflection and touches on the issue of the apparent facticity of imparted knowledge. There is a commonality in these definitions of social learning in that they emphasize the uncovering and delineation of assumptions and preconceptions.

Wynne (1992) states that "Social learning can be defined as this kind of progressive, reflexive unearthing and negotiation of the pre-commitments shaping knowledge frameworks. It is reflexive in the sense that it critically examines and enlarges the self-knowledge of the social actors involved." Wynne's definition of social learning posits the examination of assumptions and pre-commitments through reflection as important in understanding the development of knowledge. The process of reflexive unearthing encourages the uncovering of the way in which facts are constructed and communicated.

Garmendia and Stagl (2010) review various approaches to social learning and the way in which knowledge creation relies on a critical reflexive process. They regard the social learning approach as looking beyond the acquisition of facts by individual actors. They suggest that finding new facts and reflecting on assumptions in our knowledge forms an important basis for the formation of social knowledge and an important component of social learning.

Tippett et al. (2005) comment that social learning involves understanding the frames of reference, which actors bring to deliberation and this requires making explicit the assumptions and perceptions that they have. This will involve them expanding their own frame of reference. This is relevant to understanding critical reflection and how facts are created in that examining assumptions makes clear how knowledge is dependent on various presuppositions rather than being simply factual. According to Tabara and Pahl-Wostl (2007) social learning should provide opportunities for critical mutual reflection and the development of an awareness of taken for granted assumptions and cultural frameworks. This would enable people taking part in such social learning to be aware of the way in which facts are produced.

Schusler, Decker and Pfeffer's (2003) notion of unrestrained thinking, which is posited as fostering social learning, is relevant to the notion of critical reflection. Unrestrained thinking involves thinking beyond what one normally does and learning in ways that might be otherwise prevented. This looser, unrestrained form of thinking may lead people to see new possibilities for working together and changing attitudes towards opposing points of view - a major benefit of deliberation (Schusler, et al., 2003). Unrestrained thinking encourages publics to circumvent the way in which facts might be presented and accepted at face value.

Throughout these discussions of social learning, critical reflection, which enables examination of assumptions and encourages more flexible thinking and the examination of the way in which facts are created, has become an important aspect of social learning. This article seeks to explore how the uncovering of facticity, through critical reflection, can enhance social learning processes. We focused on the development of a public's capacity to reflect on and question scientific and technological knowledge presented to them and in this way not readily accept the facticity of expert knowledge. The workshop process developed in this study was designed to promote critical reflection on the science and technology of water reuse. It encouraged participants to question the expert information provided to them. Potter's concept of facticity was used to analyse the discussion in the workshops in order to assess how critical reflection, encouraged in the workshop process, enabled citizens to question the scientific information provided to them.

Potter (1996) describes facticity in terms of reificatory and ironizing discourse and offensive and defensive rhetoric. Reifying discourse constructs the world as solid and factual, from the abstract to the material. The use 
of reifying discourse within the scientific and technological knowledge presented to citizens does not immediately indicate that the science under discussion has been subject to in depth questioning and review of alternative viewpoints. When participants use reifying discourse to discuss such knowledge they are accepting the expert knowledge provided as factual. On the other hand, ironising discourse undermines or counters versions of the world. Whether the facticity of expert knowledge is questioned within social learning in an engagement process depends on the way in which the expert information is provided and whether alternative viewpoints are addressed. The use of ironizing discourse within participants' discussion of such knowledge indicates questioning and deliberation about the expert scientific information provided.

Potter describes offensive rhetoric as undermining alternate descriptions by reworking, damaging or reframing them. If offensive rhetoric has been utilized by participants in discussing expert information it suggests that participants actively undermine the description of the science or technology being provided by the expert, thus rejecting any apparent facticity of the expert knowledge provided. Defensive rhetoric resists discounting or undermining indicating acceptance at face value of the information presented. Use of such rhetoric to discuss the information provided by experts who are imparting knowledge indicates a reticence to question the facticity of the knowledge they are presenting.

Potter's framework of rhetoric and discourse was used to assess the nature of knowledge constructions taking place in a social learning process. Critical reflection on the expert knowledge provided to the public and a reticence to accept the facticity of such knowledge is regarded as essential for a social learning process on new technology. The use of ironizing discourse and offensive rhetoric suggests that effective social learning has taken place through critical reflection achieved by questioning of expert information. The use of reificatory discourse or defensive rhetoric suggests a resistance to the acceptance of alternative viewpoints and minimal examination of the apparent facticity of imparted knowledge.

The concept of facticity has had minimal empirical examination. Rapley (1998) examined facticity in relation to the racism and dogmatism of an Australian politician's speech and the discursive devices she used in establishing such facticity. The way in which the contents of the speech are constructed as indisputable fact are analysed along with the way in which offensive and defensive rhetoric are employed. Rapley also analyses the way in which facticity is warranted by consensus and corroboration thereby bolstering the external validity of a claim. A further means of constructing facts are the ways in which descriptions are considered external to the speaker. Techniques for doing this include the use of empiricist discourse such as testing and experimentation and various kinds of narrative constructions such as the use of bureaucratic reporting systems. Rapley also utilises Potter's concept of category entitlement, which refers to expectations that a particular type of person would have particular knowledge or would be ignorant of particular details about an event. These concepts were utilised in assessing the dialogue expressed in the deliberative workshops developed on water reuse.

Public engagement on water reuse should provide citizens with the opportunity for social learning about the science and technology of water recycling infrastructure. Use of reificatory discourse and defensive rhetoric, and in some cases offensive rhetoric in discussion of such infrastructure, suggests that citizens are not engaging in critical reflection of the knowledge provided. When citizens engage in ironizing discourse it suggests that they are able to challenge analyses and ascertain whether such analyses are biased towards a particular perspective which may be scientific, customary, local or technical.

Whether these ways of dealing with information are engaged in by publics were explored in the analysis of a series of workshops, which were conducted on the topic of recycled water. Instances of various forms of discourse and rhetoric were catalogued in the proceedings of these workshops, not for the purpose of demonstrating in this instance that publics necessarily engage in these processes as a result of a social learning process involving critical reflection, but that they could occur. The workshops were oriented to encouraging critical reflection, and hence may have served to encourage various forms of discourse and rhetoric which indicate a resistance to the apparent facticity of the scientific and technological knowledge of recycled water. The nature of the research conducted in this project is that of investigating whether these speech forms occur and in this respect the research method in this study is akin to observation of social interaction within the deliberative workshops developed for the project. Future research could assess through experimental methodology whether critical reflection leads to a reduction in the perception of facticity.

\section{Methodological Process}

In this study, participants took part in deliberative workshops in four regions on the east coast of Australia, where there are agricultural, residential or planned residential recycled water systems: in the Shoalhaven region and in Gerringong-Gerroa on the south coast of New South Wales, where there are agricultural reuse systems in 
operation; Coomera in southeast Queensland, where a dual reticulation system had been installed in a new housing development, but was not yet operational and in Newington in New South Wales where a recycling system, with application to gardens and toilet flushing, had been in operation for several years. The workshops conducted were part of a study on public participation method and social learning in relation to water reuse (Russell, Lux, \& Hampton, 2009). This was not an actual public participation process but was designed to be an emulation of how such a process could operate. Sixty two people participated in 8 groups, and were selected by systematic sampling of the local telephone directory and municipal council lists of residents, and were paid a small fee for their participation.

In a series of two deliberative workshops, utilising focus group method, in that the group process followed a discussion guide and focus group style questioning was used to promote discussion, participants were first questioned about their understanding of water resources, potable water and local water recycling schemes and what further knowledge they required about such schemes. An audio-visual presentation was provided to explain the nature of the local water resources. The ensuing discussion provided an opportunity for assessment of knowledge on and evaluation of water recycling. In the second deliberative workshop participants were provided with information through an audio-visual presentation about water recycling technology and its effectiveness and further details on the recycling scheme in their area. This information was obtained from university academics in the area of water recycling, including engineers and biochemists and information available from scheme managers. The discussion leaders created a process within the groups in which the participants were encouraged to question the information provided. If there was a controversy concerning water recycling, this was discussed with participants. These controversies usually concerned the measurement and treatment of impurities in waste water. Membranes used to treat waste water were given to the groups to examine. The sizes of the impurities in relation to the pores of the membranes were discussed. The possibility of failures in the membranes and damage to the membranes was also raised. The provision of this information and the ensuing discussion provided an opportunity for assessing how participants reacted to the provision of expert knowledge and whether they were prepared to question such knowledge, particularly when encouraged to do so.

As the last two series of workshops dealt with actual residential water recycling schemes, participants were asked to complete questionnaires at the end of the workshop on their attitudes towards using recycled water for various domestic purposes. The questionnaires used traditional Likert scales, which assessed attitudes towards comfort with various uses for recycled water and perceptions of health risks with those particular uses.

The workshop process developed for the project on water reuse depended on the communication of expert knowledge and subsequent deliberation about this knowledge. The public acceptance or rejection of expertise is partly dependent upon perception of the origins of such expertise. An expert might be accepted by a particular public if that public has prior knowledge of that person or organization to which the expert belongs (Turner, 2006). An expert might have experience which extends the public perception of that expertise to another situation. The public acceptance of that expertise might facilitate public acceptance of the scientific and technological knowledge imparted by that expert as being factual, if there is acceptance of the social group from which the expert originates. Within the workshops the presenters were identified as social scientists from a university who had developed expertise in the area of water reuse that was sufficient for the conduct of the workshops.

Collins and Evans (2006) distinguish between interactional expertise--enough to do a sociological analysis; and contributory expertise--enough expertise to contribute to the science of the field being analyzed. The workshop presenters were social scientists who had sufficient knowledge of the technology involved in water reuse to be considered as having interactional expertise. The scientists and engineers advising the presenters had contributory expertise in the area of water reuse and were involved in scientific research in the area.

In this project, expert knowledge of the engineers and scientists involved in the project was translated to the lay public through the workshops. Horlick-Jones, Rowe and Walls (2007) refer to the 'translation quality' of expert information requiring a plurality of information from a variety of expert sources, which enable a variety of viewpoints to be considered. Collins and Evans (2006) also discuss the act of translation which requires interactional expertise in each of the areas between which translation is required. Contributory expertise is not required for translation as no new knowledge is required.

The dialogue occurring in the workshops was audio recorded and transcribed and analysed with NVivo qualitative analysis software (NVivo, 2009) using the following categories to characterise the reactions of participants to the knowledge presented to them in the workshops:

Reifying discourse -- the world is constructed as solid and factual and scientific and technological knowledge is 
perceived as such;

Ironising discourse -- undermines or counters versions of the world thereby reducing the apparent facticity of scientific and technological knowledge being considered by participants;

Offensive rhetoric -- oriented to undermining the knowledge of experts by reworking, damaging or reframing such knowledge and thereby decreasing the perceived facticity of expert knowledge;

Defensive rhetoric -- resists discounting or undermining which the alternative description provides and thereby increases the facticity of the knowledge which is the focus of discussion;

Activity being enhanced through consensus and corroboration, thereby bolstering the external validity of a claim;

Descriptions seen as more factual because they are considered external to the speaker through such things as empiricist discourse, narrative constructions or category entitlements.

The following statements, taken from the various workshops, have been classified as representing these concepts.

\section{Statements Indicating Acceptance or Rejection of the Perceived Facticity of Expert Knowledge}

\subsection{Offensive Rhetoric towards Expert Knowledge}

In the following examples, offensive rhetoric is used to indicate disagreement with or tentative rejection of expert knowledge. These statements concern potable and recycled water. The first participant questions the general strategy of water management. This does not challenge the scientific information presented but questions the general strategy of the government provision of water.

That's the biggest issue I have got, pumping it out into the ocean. I think it's sheer waste, absolutely stupid. Much better if they put a curve in the pipe and send it out west or whatever. I know it's not a cheap thing to do, they've got to do something different. (Coomera, fourth group, second session)

The following participant, in another group, questions the purity of potable water and then recycled water, which is provided through the local water supply infrastructure, and in this respect is engaging in offensive rhetoric in that she challenges, through comparison with the quality of potable water, the expert view (provided by the recycling facility engineer) that tertiary treated wastewater is suitable for some forms of reuse.

Probably, I don't know, I haven't tasted it, but, I think, well you normally drink the water, I even filter the normal water, because I don't, I think it's, it still tastes like something, and water shouldn't taste like anything. So I filter it, and then it doesn't taste like anything any more, but I don't know, like, the recycled water already looks different, so I don't want to try and taste it, because I think you can taste it as well! (Newington, first group, first session)

Caution with expertise is justified through use of the example of the Challenger space shuttle disaster - the possibility of technological failure is alluded to. The reliability of the technology is called into question through the use of a category entitlement which posits technology as having possible failure scenarios.

Like we had the Challenger failure, you know, the space shuttle went 70 miles up and boom that was it, because of a technological failure. You might have a technological failure here, or do you trust it enough? (Newington, first group, second session)

In the following example the participant is questioning the cost of providing two sets of pipes. In this respect he is questioning, through the use of offensive rhetoric, the expert technological knowledge provided about the provision of water.

That's an environmental impact. And now I'm wondering which is, which, you know, have I, by doubling, if we were to double all the copper pipes that have to go to people, you know, you've got to have twice as much mains, twice as much pipes to go to people's house, that may put more damage onto the environment than what we save in the water, so I'm now wondering, I mean, I feel okay now, because it's already there, but if so the extra copper piping, and what I am saving the environment. (Newington first group, first session)

In the following example the participant disagrees with the expert technological knowledge provided by the local council and this could be considered a form of offensive rhetoric representing disagreement with the knowledge about the purity of potable water, however the participant concludes that recycled water is acceptable. His ultimate acceptance of recycled water is based on trust rather than deliberation. This issue of trust was not raised intentionally as part of the social learning process in the workshop but the matter was discussed in the interaction on water reuse. 
Can I just say that that is as much bullshit as anything else. So the Council gives you a piece of paper and say, 'we've monitored the water and its 99.9 percent.' And the reality if you test your own water the difference is going to be chalk and cheese. I mean you can put anything on paper, but you don't necessarily believe it. So you have to trust what is coming out of the tap. So I would have the same trust, call it blind faith, in the recycled. (Coomera, second group, first session)

The use of offensive rhetoric in the following example undermines the expert view that recycled water is safe and enhances the participant view that it is not safe to use.

But we've got two bits of evidence, one is the car, if you don't wash it off (the car), the fine, the material that's suspended in it starts showing, and it shows up in the toilets, you know, and after a couple, a month or two, you have to bleach the toilet, or it's brown (Newington, first group, first session).

\subsection{Defensive Rhetoric towards Expert Knowledge}

In this example expert knowledge concerning the safety of using recycled water is defended because it has been publicly acknowledged, which enhances the participants' view of its facticity.

Because, maybe I'm a bit gullible, naïve, one would think it wouldn't be provided so publicly if there was any major risk? You know? (Nowra, second session).

Facticity is supported through the publication of reports. The report is a narrative form which was utilized by participants to externalize and defend expert information.

It's safe and it's been regulated to an extent that everyone knows it is safe following reports (Nowra, second session)

\subsection{Reification of Expert Knowledge}

The following excerpts are examples of how some participants put their faith in expert knowledge. In the first set of examples there is a relinquishment of responsibility to the expert and in one case a justification for putting such trust in experts. The role of expert is reified in these examples; there is also the use of category entitlement in that there is the expectation that expert knowledge can be relied upon. The category of expert is one that was trusted by participants and they did not question expert action. The type of expertise was not called into question and could be considered taken for granted, with the assumption that the expert has been given official recognition. In this way the category of expert is used to enhance the external validity of a knowledge claim through a process of corroboration.

In the following example, the actions of a technician or salesperson in testing the purity of the water are regarded by a participant as being valid and in this respect the facticity of the judgment on purity is enhanced through the ascription of expertise to the salesperson/technician.

If you get a glass of tap water and what are those little tablets? Remember that guy that came round with the filter system? We put in one of the sink top filters that connects to the pipe, and you could see the difference in the colour. The tap water went pink when he dropped this little tablet in it, to show you. Then the filtered water stayed clear. And the pink was obviously the impurities that were still in the tap water. (Coomera, first group, first session)

In this example the integrity of the category of expert is maintained.

What in the people who are developing it at the end of the day, they've got to believe that they might be drinking it. So I think, as long as I know about it (Coomera, fourth group, second session).

This short statement expresses the trust expressed through the category entitlement of expert.

Because they're the experts (Coomera, fourth group, second session).

In this example the opinion of expertise is respected and the doubts expressed by a public are discounted thus enhancing the facticity of expert opinion.

Yes, well that's there, before we say that we want it to a certain level, unless you really know what you're talking about, well, you're either going to stop the progress of it for everybody, because somebody is, which often happens in Queensland, I don't know (Coomera, fourth group, second session).

In the following example, expertise within a local authority is respected and trusted at face value and in this respect is regarded as factual.

I said earlier Peter... Peter I said earlier that I thought the water was about 98 point something percent which meant that I would drink it. So obviously if you've got a sprinkler system going and you've got young kids 
running on the garden, you don't put barbed wire up and say don't run on the garden kids. So the Council must know, which is why I'm asking the question...Robert's description of the filtering system was excellent, but I'm not concerned. I've got to trust the Council that we will continue to get whatever their stat is, let's assume 98 percent, now they're going to continually deliver us 98 percent pure water. Cause you can't go hang on I want to monitor and see how dirty or clean it is before I turn it on, you got to have a bit of blind faith (Coomera, second group, first session).

In this excerpt there is a willingness to trust expert information.

So that's why some countries then put $5 \%$ of the recycled water back into their main storage because it's so close, that they, you wouldn't notice that it's information available to us, and the source of that information was reliable and well monitored (Coomera, fourth group, second session).

In the following example, expert knowledge is supported through reification of such knowledge through the assumption that if such knowledge is made public then it must be credible. This is another example of externalization of expert information. There is an assumption that the expertise is credible and has had some form of external recognition.

Because, maybe I'm a bit gullible, naïve, one would think it wouldn't be provided so publicly if there was any major risk? You know? (Nowra, second session).

\subsection{Ironizing Discourse}

Ironising discourse was not readily apparent in the workshops. This form of discourse may not be readily engaged in and may require particular confidence in one's scientific and technological knowledge about recycled water before irony is engaged in. There was some ironizing discourse engaged in but that was in relation to public knowledge as referred to in the following excerpt.

It's beginning to change, but you just don't know what you've got until it's gone, and then it's only the real, you know like getting a big shock that all these councils are actually starting to change, and I just don't know why that would be illegal, and also rainwater reuse. Like what's wrong with putting your grey water out on the back lawn? From the shower or whatever? Like? I mean? What's the risk of it, you know, if your next door neighbour has hepatitis and you go round? I don't know, licking their back lawn or something. (LAUGHTER) I just don't know if that's such a big risk compared with having no water. You know? (Nowra, second session).

In the following excerpt there is use of irony in a discussion of the claims of organisations that their bottled spring water is natural.

In New South Wales they have to add five additives to that water before they can sell it. They literally have to add five additives to that natural spring water. They sell it as natural spring water. They have to add five additives to that water before they are legally allowed to sell it. There's your natural spring water. They have to add those five additives. (Coomera, second group, second session)

\subsection{Outcomes of Social Learning}

In order to provide an initial evaluation of the possible outcomes of this social learning process, in which critical reflection was encouraged, the participants in the Coomera and Newington case studies were administered questionnaires, which assessed their attitudes to recycled water at the end of the first and second workshops. The workshops were not intended to promote or discourage use of recycled water but to encourage critical reflection on water reuse. The questionnaires provide some insight into the possible effects of possibly enhanced critical reflection on such a process, which could be evaluated through experimental method.

Paired t-tests indicated that participants in the Coomera workshops, were more comfortable at the end of the second workshop using recycled water for flushing toilets $(t(17)=1.81, p<.04)$ and perceived less health risks in doing so $(t(17)=1.87, p<.03)$. Newington participants were more comfortable with the possibility of showering with recycled water $(t(13)=1.6, p<.06)$ and perceived less health risks for such a use $(t(13)=4.16, p<.01)$. Newington participants were also more comfortable drinking recycled water $(t(13)=4.05, p<.01)$ and perceived less health risks in doing so $(t(13)=3.12, p<.01)$. The occurrence of type 1 error is possible with the use of multiple t-tests but this change in attitude was maintained when multivariate analysis of variance, which accounts for this type 1 error, was utilised (Wilks criteria $=.18, F(6,8)=6.03, p<.01$ ). However, it is acknowledged that for the use of multivariate statistical techniques, the sample sizes for these two instances of the workshop method were quite small.

It is possible that these changes in attitudes were made after a process of critical reflection and the results indicate that it would be worthwhile evaluating this change process through experimental method with the use of 
experimental and control groups.

\section{Discussion}

These excerpts demonstrate how the concept of facticity, and associated discourse and rhetoric, is of use in describing public reactions to the science and technology of water recycling. In a climate where there is encouragement to question expert knowledge there were indications that a public will readily use offensive rhetoric towards expert knowledge provided. These excerpts demonstrate the various devices, which publics can use in response to the presentation of expert knowledge. In some cases they reify the role of expert or use externalizing devices in response to the knowledge presented. In some cases offensive rhetoric is used to question expert knowledge.

The publics sometimes went along with the questioning of the scientific and technological information provided. They were prepared to question the information and not accept it at face value. The excerpts on offensive rhetoric show that the public is prepared to question scientific and technological knowledge when the ground rules of a group give encouragement to such questioning.

The possible impact on social learning in the workshops was that participants were sometimes accepting of the uncertainties involved with the scientific and technological knowledge provided. In some cases participants expressed the view that they were more accepting of the use of recycled water. The way in which they evaluated water reuse was dependent upon the discursive context. This suggests that policymakers do not need to engage in marketing campaigns, which are designed to persuade the public to accept water reuse, but should simply provide scientific and technical knowledge to citizens and encourage them to question such knowledge so that they can form their own judgments about the validity of the knowledge provided. This study suggests that a public is capable of developing a reflexive capability in social learning, as suggested by Wynne (1992) and Keen et al. (2005).

The social scientists involved in this research maintained the translation quality of the information provided by other experts, who were not present at the workshops and assumed interactional expertise. In one case one of the experts relied upon for contributory expertise came to a workshop to ascertain whether the participants were understanding the information she had provided.

The categories of reificatory discourse and offensive rhetoric were readily utilized in categorizing the dialogue about expert information on recycled water. Participants utilized these forms of speech in discussing expert information. Although the workshops encouraged questioning of the information, there were numerous examples of reificatory discourse.

In this process of social learning we were encouraging questioning of the scientific and technological knowledge provided about water reuse. There were some examples where this questioning of 'the facts' had taken place but there were numerous other examples of the acceptance at face value of the expertise provided in the workshops.

Further research is needed to refine the way in which experts provide information. We intend to involve experts in providing information to the public along with demonstrations of waste water filtration technology. We would like to see a readiness amongst experts to have their expert information questioned rather than expecting a public to accept the facts as they understand them. The questioning of scientific and technological knowledge provided in a public engagement program is an important part of citizens' social learning and should be incorporated in educational activities in such engagement.

\section{References}

Agranoff, R., \& McGuire, M. (2004). Collaborative Public Management: New Strategies for Local Governments. Washington, DC: Georgetown University Press.

Burchell, K. (2007). Empiricist selves and contingent "others": the performative function of the discourse of scientists working in conditions of controversy. Public Understanding of Science, 16, 145-162.

Chalmers, I. (1982). What is this thing called science? Brisbane: Queensland University Press.

Collins, H. M., \& Evans, R. (2006). The third wave of science studies: studies of expertise and experience. In E. Selinger, \& R. P. Crease (Eds.), The philosophy of expertise (pp. 39-110). New York: Columbia University Press.

den Heyer, G. (2011). New public management: A strategy for democratic police reform in transitioning and developing countries. Policing: An International Journal of Police Strategies \& Management, 34(3), 419-433. http://dx.doi.org/10.1108/13639511111157492 
Eden, S. (1996). Public participation in environmental policy: considering scientific, counter-scientific and non-scientific contributions. Public Understanding of Science, 5, 183-204. http://dx.doi.org/10.1088/0963-6625/5/3/001

Fischer, F. (1993). Citizen participation and the democratization of policy expertise: from theoretical inquiry to practical cases. Policy Sciences, 26(3), 165-187. http://dx.doi.org/10.1007/BF00999715

Fischer, F. (2000). Citizens, experts and the environment: The politics of local knowledge. Durham NC: Duke University Press.

Fischer, F. (2003). Reframing public policy: discursive politics and deliberative practices. New York: Oxford University Press.

Garmendia, E., \& Stagl, S. (2010). Public participation for sustainability and social learning: Concepts and lessons from three case studies in Europe. Ecological Economics, 69(8), 1712-1722. http://dx.doi.org/10.1016/j.ecolecon.2010.03.027

Horlick-Jones, T., Rowe, G., \& Walls, J. (2007). Citizen engagement processes as information systems: the role of knowledge and the concept of translation quality. Public Understanding of Science, 16(3), 259-278. http://dx.doi.org/10.1177/0963662506074792

Keen, M., Brown, V. A., \& Dyball, R. (2005). Social learning: a new approach to environmental management. In M. Keen, V. A. Brown, \& R. Dyball (Eds.), Social learning in environmental management (pp. 3-21). London: Earthscan.

NVivo. (2009). QSRNVivo version 8sp4 QSR International proprietary limited.

Petts, J. (1997). The public-expert interface in local waste management decisions: expertise, credibility and process. Public Understanding of Science, 6(4), 358-381. http://dx.doi.org/10.1088/0963-6625/6/4/004

Potter, J. (1996). Representing reality: discourse, rhetoric and social construction. London: Sage publications.

Radcliffe, J., \& Dent, M. (2005). Introduction: from new public management to the new governance?. Policy \& Politics, 33(4), 617-622. http://dx.doi.org/10.1332/030557305774329172

Rapley, M. (1998). 'Just an ordinary Australian": Self-categorization and the discursive construction of facticity in 'new racist' political rhetoric. The British Journal of Social Psycholgy, 37(3), 325-344. http://dx.doi.org/10.1111/j.2044-8309.1998.tb01175.x

Reich, R. B. (1990). Public management in a democratic society. Englewood Cliffs, N. J.: Prentice-Hall.

Russell, S., Lux, C., \& Hampton, G. R. (2009). Beyond "Information": Integrating consultation and education for water recycling initiatives. Society and Natural Resources, 22(1), 56-65. http://dx.doi.org/10.1080/08941920801910666

Schusler, T. M., Decker, D. J., \& Pfeffer, M. J. (2003). Social learning for collaborative natural resource management. Society \& Natural Resources, 16(4), 309-326. http://dx.doi.org/10.1080/08941920390178874

Tabara, J. D., \& Pahl-Wostl, C. (2007). Sustainability learning in natural resource use and management - art. no. 3. Ecology and Society, 12(2), 3-3.

Tippett, J., Searle, B., Pahl-Wostl, C., \& Rees, Y. (2005). Social learning in public participation in river basin management - early findings from HarmoniCOP European case studies. Environmental Science \& Policy, 8(3), 287-299. http://dx.doi.org/10.1016/j.envsci.2005.03.003

Turner, S. (2006). What is the problem with experts?. In E. Selinger, \& R. P. Crease (Eds.), The philosophy of expertise (pp. 159-186). New York: Columbia University Press.

Waste Management Environment. (2012). Recycling against the "instincts" say Toowoomba residents. Environment Business Media Retrieved February 21, 2012, from http://www.wme.com.au/categories/water/FEB5_06.php

Webler, T., Kastenholz, H., \& Renn, O. (1995). Public participation in impact assessment: a social learning perspective. Environmental Impact Assessment Review, 15(5), 443-463.

Wynne, B. (1992). Risk and social learning: reification to engagement. In S. Krimsky, \& D. Golding (Eds.), Social theories of risk. Westport, USA: Praeger. http://dx.doi.org/10.1016/0195-9255(95)00043-E 